\title{
A SEARCH FOR IDENTITY IN JULIA ALVAREZ'S HOW THE GARCÍA GIRLS LOST THEIR ACCENTS
}

by William Luis

The displacement of Caribbean people from their islands to the United States, for political or economic reasons, has produced a tension between the culture of the country of origin and that of the adopted homeland, one representing the past and the other the future of the immigrant. As time passes, for the immigrant, the rupture with the past, strongest in political exiles, is transformed into a desire to recover a lost moment in time. But the past ceases to exist as an island reality and is interpreted from the perspective of the mainland culture.

The political migration of Dominicans from their island of origin to the United States is contemporaneous with the fall of Gen. Rafael Leonidas Trujillo and the first wave of Cuban exiles at the beginning of the 1960s. During his dictatorship, Trujillo had absolute control over the military, the economy, and the people and, except for a select group, he prevented anyone from leaving the island. During this stage of Dominican history, those who did abandon the island with or without the dictator's consent sought political exile.

The situation changed radically after the dictator's death and the U.S. invasion of the island, which foiled any attempt to restore Juan Bosch to the presidency or convert the Dominican Republic into another communist Cuba. With the direct U.S. involvement in the internal affairs of the Dominican Republic and the support of Joaquín Balaguer's presidency, the number of Dominican exiles increased and their conditions changed in character, from political to economic. The Dominican migration to the United States has steadily risen, making Dominicans, second to Puerto Ricans, the largest Hispanic group in New York. ${ }^{1}$ However, as with other immigrant groups, Dominicans found themselves looking back to understand their present and future. If writers on the island were trying to come to terms with the Trujillo dictatorship and the U.S. invasion of their country, those who traveled to the mainland wanted to recover a lost origin.

The Puerto Rican economic migration associated with Operation Bootstrap, after WWII, and the Cuban political exodus, related to the Castro takeover in 1959, produced a generation of Latino writers born or raised in the United States. The Dominican migration, which was first political and later economic, would also count among its members a significant number of writers. And just as the other immigrants or sons of immigrants have documented their experiences mainly in the cities in which they live, Dominican-American authors would also do the same, some of them writing in Spanish and others in English. ${ }^{2}$ In her How the García Girls Lost Their Accents, 
the Dominican-American writer Julia Alvarez depicts a search for identity motivated by a tense struggle between Hispanic and North American cultures.

The political exile of the García family, in How the García Girls Lost Their Accents, takes place during the Trujillo dictatorship. In recreating the past, the narrator tells us that Carlos García, with the assistance of Mr. Victor, an American diplomat and member of the Central Intelligence Agency, planned to assassinate the ruthless Trujillo. But the attempt failed when the State Department did not support the plan Mr. García had been asked to organize. Accosted by Trujillo's henchmen, Mr. García received a fellowship from the United States that allowed him to leave the Dominican Republic and work as an intern in a hospital in New York City, where he moved with his wife and four daughters.

Even though How the García Girls Lost Their Accents is written in English and appears to have more in common with North American than Hispanic literature, the novel's structure recalls that of Alejo Carpentier's "Viaje a la semilla" [Journey Back to the Source]. Carpentier's story is narrated backwards; that is, it begins in a present or toward the chronological ending of the narration and ends at the beginning, at the chronological origin of the events narrated. Similar to Carpentier's story, How the García Girls Lost Their Accents describes the most recent events and ends with the earliest ones; that is, it starts during the period of 1989-1972, when the four sisters are adults and reside in the United States, and concludes during the 1960-1959 period, when they were young girls living in the Dominican Republic. The beginning of the narration is the end and the end is the beginning and consequently the novel has two beginnings and two endings, physical and chronological ones. ${ }^{3}$

In Carpentier's work, the black character, a practitioner of African religion, perhaps Melchor, with extraordinary gestures sets into a regressive motion events associated with the life and death of the Marqués de Capellanías. As in Carpentier's story, Alvarez's novel also refers to the magic of African religion, expressed mainly by Chucha and Pilar, the two old Haitian women who practice voodoo. Pilar, who is present at the end of the narration, which is the chronological beginning of the story, causes Yolanda, in particular, to experience the terror of the coal shed. Yolanda is the author's alter ego, and the coal shed occupies a central space in the narration and is the source of Yolanda's nightmares. The coal shed is the space of terror, represented by Pilar's stories and the mother of the kitten Yolanda wants to raise; of pleasure, when Mundin asks her to show him her private parts; and of fiction, when she has to lie to avoid tía Carmen's punishment. The coal shed is the origin of memory and the story, which motivates Yolanda to return to the island, possibly to stay forever, and Alvarez to write her story, as we shall see later. The novel is an attempt to understand memory, the past, and a time before the sisters lost their innocence and accents.

How the García Girls Lost Their Accents describes the exile of the García family from the Dominican Republic to the United States, and the reasons why it had to leave the motherland, origin, and travel to the mainland, where their lives continued to unfold in the present. Carlos García's action, to plan an attack against a high dignitary, Trujillo, was a theme developed in Marcio Veloz Maggiolo's El prófugo (1962), but was already present in Carpentier's El acoso (1956). This aspect of García's life resembles that of many political exiles who, during the 19th century, conspired against Spain 
and sought refuge in the United States where many of them continued their struggle against the colonial government. Like the first wave of anti-Castro exiles, the Garcías were privileged and professionals. The grandfather had studied in the United States, held a diplomatic appointment, and owned land where the members of the family constructed their homes, with servants and private guards. In the Dominican Republic, the García daughters attended a school for American children. When Mr. García won the grant that allowed him to abandon the island, the grandfather did not consent that his son and family live like commoners. And on more than one occasion, the reader is told that the parents only shopped at FAO Schwarz, one of the most complete and expensive toy stores in New York City.

In the United States, the García sisters continued to receive the best education money could buy. But the events had changed; they now experienced life in the United States from a different point of view, not as members of a privileged class associated with the Dominican Republic, but as common Hispanic immigrants. The García girls are the objects of discrimination both in and outside school. Carla, the oldest, experiences rejection when a gang of boys follows her, throwing rocks and yelling "Go back to where you came from, you dirty spic!" These are the same words La Bruja uses in a section narrated by Sandi (HGG 153,171). This subtext in Alvarez's novel recalls the Puerto Rican literature of the Generation of the 1940s, which documents the life of Puerto Ricans who left the island after Operation Bootstrap was put into effect, but has more in common with the works of the sons and daughters of Puerto Rican immigrants as portrayed in Nuyorican literature, written primarily in English. The works of poets such as Pedro Pietri and Tato Laviera and narrators such as Nicholasa Mohr and Piri Thomas document, not so much the migratory process generated by Operation Bootstrap, but the lives of Puerto Ricans once they arrived in New York. Alvarez's contribution to this literature shows that North Americans do not differentiate between economic and political exiles. They also do not distinguish between the different Hispanic-Caribbean groups-that is, Cubans, Puerto Ricans, and Dominicans-for the García girls have been reduced to common people and are treated with disdain.

The discrimination of North Americans toward Hispanics in Alvarez's work is not unique but appears to be a part of any migratory process, including that inside the Dominican Republic. The reaction North Americans have when they see Carla García is similar to the one she and other members of her family exhibit toward servants in general and Haitians in particular while living in the Dominican Republic. In fact, their characterizations contain racial overtones. For example, Chucha was not a "cafécon-leche" Dominican, but a "blue-black" Haitian; that is, she was very black and had problems in pronouncing some words in Spanish and anything that had a " $\mathrm{j}$ " sound. This situation parallels that of the García girls; in the United States, the girls spoke with an accent that their father still conserves. From the point of view of a regressive narration, the racial prejudice existed in the Dominican Republic well before the García family left the island to live in the United States. But the prejudice that the girls experience in the United States, toward the beginning of the narration, allows them to uncover an earlier one found in the Dominican Republic, toward the end of the novel. 
How the García Girls Lost Their Accents follows with more precision a tradition established by novels such as Pedro Juan Labarthe's The Son of Two Nations: The Private Life of a Columbia Student (1931), Humberto Cintrón's Frankie Cristo (1972), and Richard Ruiz's The Hungry American (1978), three works written by Puerto Ricans who were born on the island and lived in the United States and wrote their autobiographical narratives in English. Though Alvarez's characters are Dominicans, professionals, and well-to-do, like those of the works of the mentioned Puerto Rican writers, they live with the hope of bettering their lives in the United States. Alvarez, Labarthe, Cintrón, and Ruiz's characters live the "American Dream." By contrast, works such as Piri Thomas's Down These Mean Streets (1967) and Nicky Cruz's Run, Baby Run (1968) portray a life of despair in which the protagonist is a victim of North American society and culture.

With the passage of time, the status of the García family becomes more permanent and their lives resemble not so much those of other Hispanics living in the United States, as those of their North American counterparts. Since the family is descended from Spanish conquerors and a great-grandfather who had married a Swedish woman, we suppose that they have very little African blood. Nevertheless, Carlos García is a doctor and has a generous source of income, and his daughters are able to assimilate into North American culture with little difficulty. Certainly, this is the father's plan. They are enrolled in the best and most expensive schools for the purpose of losing their Spanish accent when speaking English, the answer to the novel's title, "How the García Girls Lost Their Accents."

As the sisters incorporate themselves into North American culture, they suffer the same problems associated with the middle and upper middle class mainstream citizens. Carla is divorced and marries her psychiatrist; Sandra starves herself in order to remain slim; Yolanda does not get along with her husband, is under the care of a psychiatrist with whom she falls in love, and ends up becoming the lover of the chair of the Department of Comparative Literature where she teaches; and Sofía is pregnant from an affair with a German she met in Colombia and whom she marries. In addition, they have forgotten aspects of their Hispanic culture and, during the father's birthday party, the band plays North American music.

Although they are Hispanic, the García girls have neglected their Dominican traditions and accepted North American culture. They are caught in the middest; that is, between the tick and the tock, something and nothing, Genesis and Apocalypse, past and future, or between North American and Hispanic cultures. ${ }^{4}$ The unstable lives of the sisters are related in part to the control the mother and father exert over their children. The parents do not adapt to the changing culture of the 1960s and treat their daughters as if they were still living in the Dominican Republic. But the daughters are also responding to the North American environment in which they live, more liberal and permissive than the traditional one known to their parents. Certainly, the North American culture plays an important role in the rebellion of the García girls. Therefore, the control the parents want to maintain over the daughters, an indication of Dominican culture, and the girls' need to rebel, a mark of North American society, results in cultural and personal conflicts. Yolanda's search for her Dominican identity must be understood within the context of the 1960s in the United States. 
The novel is narrated backwards and reveals the sisters' original language and accent, the one associated not with their adopted culture, but with their country of origin, that of the Dominican Republic. The novel starts or ends with Yolanda, the North American. That is how she is perceived when she returns to the island at the outset of the novel. Her cousin Lucinda describes her with the clothes and characteristics of a hippie; that is, a member of the youth of the decade of the 1960s who were nonconformists and experimented with drugs, or "like a missionary, her cousins will say, like one of those Peace Corps girls who have let themselves go so as to do dubious good in the world" (3-4). Lucinda also calls her "Miss America."

Yolanda had forgotten her language; she did not speak fluent Spanish and relied on English to express herself. Yolanda and her sisters' retrospective voyages represent a desire to find the original language and accent, one that was lost in the present. Yolanda did not remember what an antojito was. In Dominican lexicon, antojito has two referents: It refers to something you crave to eat, but also to the spiritual possession of someone's body. Yolanda embodies two referents, the Spanish and the North American ones. Her return to the island after a twenty-nine year absence shows that she is as much or more North American than Dominican. Nevertheless, Yolanda finds herself between two worlds; she belongs to both and to neither one of them. Her desire to return to the island in 1989, the most recent time of the novel, symbolizes a spiritual journey in search of a communion not with Dominican culture, evident during the present time of the novel, but with a mythical past associated with her childhood. Yolanda's past compares favorably with the present of her tía Carmen and her cousin Lucinda. For Yolanda, her cousin is a typical Dominican model; that is, a woman of the night. She does not recognize nor understand her family's culture: The chauffeur drives aunt Flor to church and the women await their husbands' return, knowing that they will stop to see their lovers before going home.

Yolanda is not Dominican but North American. In an essay entitled "An American Childhood in the Dominican Republic," Alvarez reveals some information about her own life. The essay could have served as the original idea for the novel or a chapter that the author excluded. In the essay, Alvarez reproduces information found in the novel. For example, she mentions that it was Mr. Victor, of the U.S. Embassy and a member of the CIA, who persuaded Carlos García to join the resistance against Trujillo, and later helped him in leaving the country, and obtaining a job with an international cardiovascular team.

However, the essay also provides the reader with explanations that the novel does not offer. For example, it explains Carlos' past. As a young man, Carlos had participated in the resistance movement against Trujillo, and sought refuge in Canada, where he lived for nine years, studied medicine, and met his wife. What is more important, it reveals that Alvarez is the second daughter and she and her older sister were born in the United States and the other two in the Dominican Republic. Her mother said that the first two were "Americanitas" and the last two "criollas." This information suggests that the author is the second daughter, and in the novel she would correspond to Sandi, and not Yolanda, the third one. We should note that Sandi is the least visible character in the novel and Yoyo plays a central role. But to undergo a search for her origins, in the novel Alvarez had to change her place of birth, from that 
of the United States to the Dominican Republic; therefore, she changes places with her sister and assumes the identity of the third child, the one who was born on the island.

A close reading of the essay and the novel shows that Alvarez altered the events of her life to create fiction. She mentions in the essay that it was her grandmother and not her father, as it appears in the novel, who brought from the United States mechanical savings boxes that were in style in the New York toy store FAO Schwarz. According to the essay, Mamita had brought the grandchildren one with a Jonah, a boat, and a whale; another with a girl jumping rope; and for her a man with a dog that jumped for a bone. In the novel, she attributes the savings box with the girl to Sandi, the one with Jonah and the boat to Yoyo, and the other with a girl and a cloud, which is not mentioned in the essay, to Carla. As we compare the novel and the essay, Alvarez does not mention the savings bank with the man and his dog in the novel, and saves it for herself; or if not perhaps we could attribute the bank to Fifi, who in the novel does not have one. This last idea indicates that she is also Fifi. But we propose that she is also Yolanda. Alvarez tells us in the essay that her grandmother had brought her a drum with two sticks inside, and that is the same one mentioned at the end of the novel, belonging to Yolanda. Moreover, it was Yolanda who liked to eat guavas, and these appear both in the essay and the novel.

If the novel is a search for the past of the Dominican Republic, the tone of the essay is different and shows a union not with the past but with the present embodied by the United States. For Alvarez, the essay represents a reunion with her place of origin, the United States; it is a desire to distance herself from her parent's culture to affirm and accept her own. Alvarez mentions that in the Dominican Republic she attended a North American school, which she preferred to the Dominican one, swore allegiance to the flag of the United States, and sang the Marine hymn. The essay concludes with the family's departure from the Dominican Republic to the United States, in the following manner:

\footnotetext{
"We're here!" my father said a little sadly. Despite my dark hair and coloring, despite the fact that I came from generations of Dominicans, I joined the Americans in clapping. All my childhood I had dressed like an American, eaten American foods, and befriended American children. I had gone to an American school and spent most of the day speaking and reading English. At night, my prayers were full of blond hair and blue eyes and snow and just such a plane ride as this one. All my childhood I had longed for this moment of arrival. And here I was, an American girl, coming home at last. (85)
}

Unlike the essay, the novel begins or ends with Yolanda's return to the Dominican Republic.

The change in perspective from the essay to the novel can be explained by considering the time in which the first was published, in 1987, and by a second autobiographical essay that Alvarez published in 1992, one year after she completed her novel. In "Hold the Mayonnaise," Alvarez offers the reader information about her 
life, this time about her husband and his "two tall, strapping, blond, mayonnaiseeating daughters" and her estrangement from the younger members of her new family - this essay is a way of bridging the distance between her and "her husband's daughters." Unlike the intent of "An American Childhood in the Dominican Republic," in "Hold the Mayonnaise" Alvarez in the second paragraph identifies herself, not as a North American, as she had done in the first essay, but as a Dominican; that is, as if she had been born in the Dominican Republic. Her desire as a young girl to assimilate into North American culture and society is not developed into a theme as an adult. The five years that occurred between the publication of one essay and the other allow Alvarez to recognize that her experiences and, most importantly, her interpretation of those experiences, have changed. In the present, she feels proud to be Hispanic. Alvarez writes in the second paragraph:

We were also Dominicans, recently arrived in Jamaica, Queens, in the early $60^{\prime}$ s, before waves of other Latin Americans began arriving. So, when we imagined who exactly my father might possibly ever think of remarrying, only American women came to mind. It would be bad enough having a madrastra, but a "stepmother" ...

All I could think of was that she would make me eat mayonnaise, a food I identified with the United States and which I detested. [... ] (Alvarez, "Hold" 14)

Alvarez, who now dissociates herself from North American culture and identifies with the Dominican one, has become the stepmother she once feared she would have. Alvarez's stepdaughters are truly American and, in comparison to their culture, she appears to be more Hispanic. For Alvarez is also struggling with her Hispanic identity. Alvarez's shift in identification, from North American to Hispanic, is associated with her family situation, but also with that imposed by her students and the times. In the second essay she questions her father's advice that to be accepted in this country you had to work hard: "In this age of remaining true to your roots, of keeping your Spanish, of fighting from inside your culture, that assimilationist approach is highly suspect. My Latino students-who don't want to be called Hispanics anymore-would ditch me as faculty adviser if I came up with that playnice message" (24). Alvarez is trying to come to terms with being Hispanic or Latino; the novel speaks of a strong Hispanic tradition and the essay of another one closely tied to a Hispanic presence in the United States. The word "Latino," which she attributes to her family, herself, and her students, refers more appropriately to Hispanics born or raised in the United States. If we consider the information provided in the first essay, Latino is an identity Alvarez can also claim since she was born in the United States. Taking into account the changing discourses, Alvarez is North American, Hispanic, and Latino, shifts that can be explained by the time elapsed between her writings: The novel was published four years after the first essay and one year before the second one; even though the narration contains information from the first autobiographical note, it is closer to the narrative tone of the second one. 
In the novel, Yolanda returns to the Dominican Republic in search of her own Dominican identity. But North American culture has changed her forever. She arrives not as a Hispanic but as a North American. Yolanda's search is part of a process of identity and pride that evolved in the decades of the 1960s and 1970s in the United States, and brought back racial and ethnic pride to African Americans and Puerto Rican Americans, among other groups. Yolanda's search must be understood within the context of that North American cultural experience; she is an independent person and is tied to the cultural experiences of her adopted country.

As a "typical American," she imposes U.S. customs on Dominican traditions. When she arrives on the island, her first desire is to eat the wild guavas, and she looks for them in the countryside, against her aunt's better judgment, who advises her of the danger of getting lost, being kidnapped, or raped. Yolanda does not return to Dominican reality, but to the past of her childhood, by means of her memory, writings, and the text.

Yolanda's return is counterpoised to that of her sister Sofía; the experience of one is distinct from that of the other. Sofía was sent to the island at seventeen, against her own free will, for admitting that the bag of marijuana the maid found was hers. During that "punishment," Fifi suppressed the feeling of liberty she had developed in the United States and accepted the customs of a Dominican woman: that is, traditional, passive, and obedient to the demands of her boyfriend, Manuel Gustavo, who was proud to assert that in the Dominican Republic "the men wear the pants."

Unlike Sofía, Yolanda traveled to the Dominican Republic by her own free will, but she could never accept the life her cousin and aunt represented. She is attracted to and repelled by Dominican culture and, in the present, she lives the tension that exists between North American and Dominican ways of life. Nevertheless, the text suggests that she will never abandon her independent habits, displayed by her venture into the countryside to find guavas. When she gets a flat tire and two men approach her, Yolanda identifies herself as an American, which saves her from the danger her aunt Carmen had foreseen. Let us remember that the Miranda guard does not want to help José, whom Yolanda had sent for aid, because he did not believe that there was a Dominican woman at that hour of the evening looking for guavas. Even though on her birthday Yolanda desires that her country of origin be her home, North American culture is an inherent part of her personality. She cannot return to the past of her innocence, of Eve in Paradise, but to a life after that origin. Eve's apple is the equivalent of Yolanda's guavas; and if the apple forced Eve from paradise, the guavas will allow Yolanda to return to the past of her memory, which initiated her voyage to her origin, the womb, as Carpentier's story outlines. Although she is seeking a moment of innocence, that of her childhood, her arrival is already contaminated by the world of adults, the present, and North American culture, which she cherishes and which determines how she interprets the past.

Yolanda is caught between two worlds, the Hispanic and the North American ones. She is a multiple being. She is North American and Dominican, she is Carla, Sandi, Sofía, and Yolanda and embodies the different narrative perspectives which their voices represent. She is also Yolanda and not Yolanda. This idea is present in the novel by the multiple names used. She is Yolanda, Yoyo, Yosita, Yo and, last but not least, 
the English Joe. And above all, she is "Yo," the Spanish first person pronoun, the "I" of the narrator. Yolanda's return to the island represents her desire to displace herself from the North American Joe to the Yolanda of her family and youth. One of her nicknames is Yoyo, which recalls the toy in constant motion, going up and down, moving from one extreme to the other, from one culture to the other, touching upon both but not remaining a part of either one of them. The protagonist's onomastic displacement will be continuous. It characterizes a search for identity, for a voice that will offer a coherent understanding of her circumstances, but also the impossibility that any one perspective exists which can explain the complexity of her inquiry. She will always be Yolanda and someone else.

Yolanda's struggle is embedded in another scene at the end of novel, which is the chronological beginning of the narration. Yet this incident is perhaps the narrative center of the novel, because after its resolution, the temporal dimension changes and follows a traditional course. I am referring to the scene in which the young Yolanda enters the coal shed with her drum and contemplates taking a kitten from the mother's litter, the one with the white boots that is distinctly different from the rest. Although Yolanda is not certain that if she plays with the kitten the mother will abandon it, she consults a hunter who happens to cross their property. He states: "Well, just as your drumsticks belong inside your drum, and dowels will not do, so a kitten belongs with its mother, and no one else will do." He continues: "While a kitten is still a suckling, it cannot, now can it, be taken from its mother to be a pet? .. . To take it away would be a violation of its natural right to live" (HGG 284, 285). The man convinces Yolanda to wait seven days until it is older, but she soon realizes the hypocrisy of the hunter who shoots at birds that have babies.

In the story, the hunter appears and disappears at the appropriate moments, and may even represent the author coming to terms with her conscience. Nevertheless, Yolanda takes the cat, whom she has named Schwarz, a symbol of the items brought to her from that store, from the litter, hides it in her drum, and returns to the house pursued by the mother cat. Although there is a parallel between Yolanda and the hunter who are both disrupting a natural order, she is more like the kitten inside the drum. Like the kitten, Yolanda was also uprooted from her nest, her childhood (perhaps seven years too early) in the Dominican Republic. And the drum beats meant to disguise the meows of the kitten represent a natural language and an imposed one, which in the years to come would cover her accent. Although we can assume that once Yolanda put the kitten out the window, it returned to her mother, Yolanda has spent the rest of her life searching for the origin of her past. From that moment, Yolanda has been haunted by the presence of the mother cat, a continual reminder to her of the incident with the kitten. The nightmares recall that past but most importantly Yolanda's own trauma of being taken from her natural environment, from her own litter; it was after this incident that her family moved to the United States.

In revisiting the past, Alvarez comes to terms with her trauma. After the description of Yolanda's encounter with the cats, the novel pivots; the events stop unfolding in a regressive manner and are now narrated in a chronological one; time is accelerated, and life appears to make sense. The novel ends in the following manner: 
Then we moved to the United States. The cat disappeared altogether. I saw snow. I solved the riddle of an outdoors made mostly of concrete in New York. My grandmother grew so old she could not remember who she was. I went away to school. I read books. You understand I am collapsing all time now so that it fits in what's left in the hollow of my story? I began to write, the story of Pila, the story of my grandmother. I never saw Schwarz again. The man with the goatee and Kashtanka vanished from the face of creation. I grew up, a curious woman, a woman of story ghosts and story devils, a woman prone to bad dreams and bad insomnia. There are still times I wake up at three o'clock in the morning and peer into the darkness. At that hour and in that loneliness, I hear her, a black furred thing lurking in the corners of my life, her magenta mouth opening, wailing over some violation that lies at the center of my art. (290)

The mother cat is a reminder of what Yolanda did, but it is also a symbol of the psychological fear of being taken away from her surroundings at an impressionable age. It is for this reason that Yolanda, the adult, must return to the Dominican Republic, not to understand the status of the present time of a privileged family or a culture struggling for democracy, but as a way of confronting her childhood and the past.

If the Caribbean was the first space of the encounter between Europe and the New World, where the different cultures clashed but also mixed, these same accounts were later repeated in other parts of the American continent. In the Caribbean, the coming together of the cultures produced a conflict of identity, which referred to the Spanish, African, Amerindian, and national components. When Caribbean people travel to the United States, the question of identity becomes even more complex and includes a North American referent. The movement back and forth between North American and Hispanic cultures has propelled Cubans, Puerto Ricans, and Dominicans into an eternal quest for identity.

\section{NOTES}

The author wishes to thank the American Council of Learned Societies for awarding him a 1994 grant to write Dance Between Two Cultures: Latino Caribbean Literature Written in the United States (1997). A version of this essay on Julia Alvarez is included in the book.

1. This was made evident most recently in Enrique Fernández, Juan González and Silvana Paternostro's "Latin Rainbow" (36-37). I would like to thank my student, David García, for making this article available to me.

2. See Daisy Cocco de Filippis and Emma Jane Robinett's Poemas del exilio y de otras inquietudes.

3. See my "Historia, naturaleza y memoria en 'Viaje a la semilla" (151-60).

4. See Kermode, in particular chapters 2 and 3. 


\section{WORKS CITED}

Alvarez, Julia. How the García Girls Lost Their Accents. Chapel Hill, NC: Algonquin Books, 1991. Subsequent references appear parenthetically within the text as HGG.

"An American Childhood in the Dominican Republic." The American Scholar 56 (1987).

"Hold the Mayonnaise." The New York Times Magazine (January 12, 1992).

Carpentier, Alejo. "Viaje a la semilla." Guerra del tiempo. México: Companía General de Ediciones, 1958.

de Filippis, Daisy Cocco, and Emma Jane Robinett. Poemas del exilio y de otras inquietudes. New York: Ediciones Alcance, 1988.

Fernández, Enrique, Juan González and Silvana Paternostro. "Latin Rainbow: New Arrivals Create a Changing City Scene." New York Daily News (March 6, 1994).

Kermode, Frank. The Sense of an Ending: Studies in the Theory of Fiction. New York: Oxford University Press, 1975.

Luis, William. "Historia, naturaleza y memoria en 'Viaje a la semilla.'" Revista Iberoamericana 154 (1991). 